\title{
CORRESPONDENCE
}

\section{CERTIFICATION OF BLINDNESS AND ASCERTAINMENT OF THE CAUSES OF BLINDNESS}

\section{To the Editors of The British Journal of Ophthalmology.}

SIRS,- The laudatory annotation upon the recent Report of the Prevention of Blindness Committee of the Union of Councils' Association for the Blind, which appears in the February issue of the Journal, scarcely does justice to the labours of a group of ophthalmic surgeons in Scotland who provided the material on which the greater part of the approved Report is based.

On page 109 due acknowledgment is made of the pioneer work of Dr. Freeland Fergus in Glasgow, but your annotation does not reveal that the Report of the Prevention of Blindness Committee of the Union of Councils' Association for the Blind is based, not upon the Report of the Council of Ophthalmologists, which appeared in the August number of the Journal (see pages 470-1), but upon important precedent work done in Scotland.

In 1922, a clinic was set up by the Mission to the Outdoor Blind for Glasgow and the south-west of Scotland, organized by Dr. Freeland Fergus. This clinic was taken over in 1929 by the Combination of Local Authorities under the Blind Persons Act (1920), for Glasgow and the south-west of Scotland area. It then came under the supervision of the Medical Officer of Health, Glasgow, its immediate direction being entrusted to Dr. James L. Halliday, of the Glasgow Public Health Staff. The success of this clinic led the Department of Health for Scotland in November, 1930 , to recommend the establishment of regional clinics throughout the rest of Scotland, based on the Glasgow model, and centred in Edinburgh, Dundee, Aberdeen and Inverness. These clinics were soon set up and are all now functioning.

In March, 1931, the Department of Health for Scotland, having observed some divergence of interpretation of the standard of blindness by different certified surgeons, called a meeting of all the ophthalmic surgeons attached to the clinics, and asked them to try and lay down more precisely the factors to be taken into account in determining whether a person was, or was not, "so blind as to be unable to perform any work for which eyesight is essential," that being the definition employed in the Blind Persons Act of 1920, and applying both to England and Scotland.

At this first general meeting a sub-committee was appointed to consider the matter further and to prepare a preliminary Report. The sub-committee met on several occasions, and the draft prepared by them was discussed at another general meeting of all the 
surgeons. With only slight modifications their recommendations were adopted by the Department, and on November 5, 1931, they were issued to the local Authorities in Scotland by the Department of Health and the Scottish Education Department in a joint memorandum. This has been the basis of certification in Scotland since that date.

The English Prevention of Blindness Committee already referred to were informed of the Scottish proposals, and their recommendations are based on, and are almost word for word, identical with ours. But anyone reading the Report issued from 66, Victoria Street, London, might naturally suppose that the standard of blindness now recommended throughout the country originated with the English Committee, but that is not the case.

I am sure I may say that my Scottish colleagues are gratified to see that their interpretation of a standard of blindness and their form of medical certificate have been so well received in England, because it would be highly undesirable to have any divergence of practice in the two countries. But it appears to me only fair and historically accurate that the names of the Scottish surgeons who did the spade work in connection with this advance in public administration should be given not less acknowledgment than those who acted on the English Committee.

The standard of blindness upon which statistics have hitherto been based varies in different countries, and this has made comparative statistics difficult or misleading. Uniformity should be aimed at.

The international Society for the Prevention of Blindness founded in 1929, have not so far tackled this problem of defining blindness. In this matter, as well as in the system of certification and provision for the blind, Great Britain may truly be said to have given a lead to the rest of the world.

The following gentlemen composed the General Committee in Scotland. An asterisk marks the names of those who served on the Sub-committee.

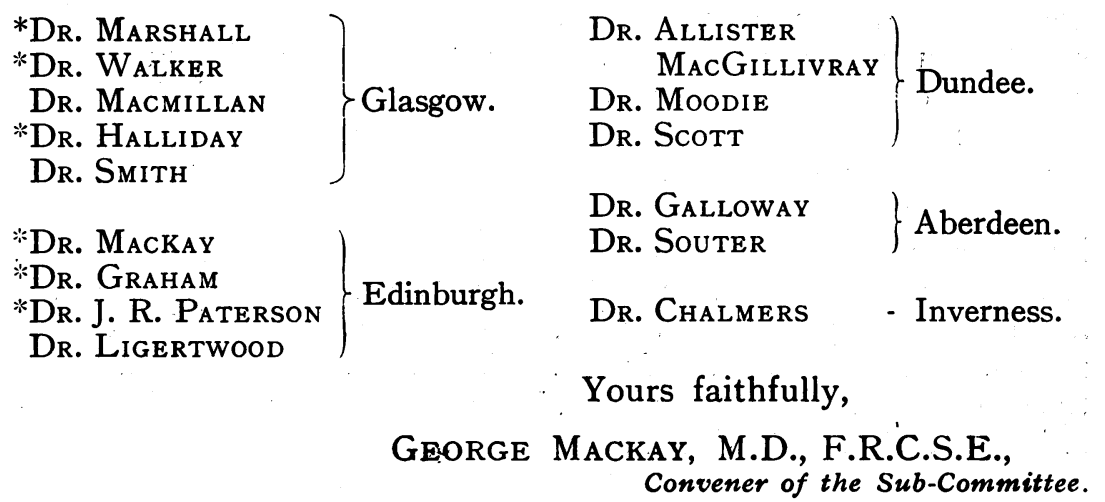

